\title{
PADRE VIEIRAE PESSOA: A LÍNGUA PORTUGUESA COMO VEÍCULO DA PÁTRIA DA ESPIRITUALIDADE
}

Hiudéa Tempesta Rodrigues Boberg*

$\mathrm{N}$ um longo percurso que envidamos em nossa tese de doutoramento, revivemos o profetismo do Padre Antônio Vieira e de Fernando Pessoa, através dos seus textos lapidares, reveladores não apenas da crença num Império por haver, mas na transformação dessa crença numa alta missão por cumprir.

Evidentemente, ambos trilharam caminhos diferentes para levar a efeito a tarefa assumida, diferenças estas nem sempre redutíveis à idéia primária de que o primeiro seria um mestre do discurso, um prosador nato, e o outro, por ser poeta, teria também escolhido a prosa para entregar-se aos devaneios poéticos.

Escolheram a prosa, no entanto, numa visão que não deveria ser, em princípio, literária, justamente por privilegiarem a forma narrativa de expressão. Por sua vez, o discurso adotado deveria abranger uma face muito especial da História, aquela que, revendo o passado, abriria perspectivas para realizações factuais ou não - no futuro.

Embora os textos estejam, atualmente, circunscritos ao plano das páginas literárias, a constituírem obras, insistimos em que, a priori, foram produzidos com um objetivo pragmático, para atingir uma meta a ser cumprida,

* Faculdade Estadual de Filosofia, Ciências e Letras de Jacarezinho. 
BOBERG, H. T. R. Padre Vieira e Pessoa: a língua portuguesa como...

pois ambos os autores acreditavam-se distingüidos para tal mister. Fernando Pessoa chega a pensar, várias vezes, em lançar mão da publicidade para tornar suas idéias conhecidas e divulgadas, com o fim de "agir sobre o psiquismo nacional" e evitar a estagnação cultural. O Padre Vieira, por sua vez, enfrentou as barras dos tribunais inquisitoriais, com a esperança, também, de fazer adeptos. Os sermões, as cartas, as entrevistas, os ensaios, mesmo que tenham recebido o trato literário característico, foram antes depoimentos, teses estudadas à exaustão, princípios e posturas de cidadãos comuns, mesmo que investidos de genialidade e transformados, com o tempo, em ícones de uma literatura ou de uma história literária.

Como cidadãos, resgataram os mitos e repensaram a história em termos teleológicos e escatológicos. Vieira, por exemplo, ao consultar as teses milenaristas, alimentava a expectativa na renovação do mundo em 1666. Tinha uma concepção providencialista da história, pois supunha a intervenção divina até nas situações mais adversas, quando Deus teria a oportunidade de revelar o seu plano divino: "Dieu a coutume d'agir par les causes secondes", diria Raymond Cantel $^{1}$ sobre as convicções do Padre. Por sua vez, Pessoa preocupava-se sobremaneira com a história psicológica da nação, a ponto de, para "agir sobre o psiquismo", arquitetar projetos de natureza patriótica. Para ele, a aspiração a um porvir glorioso ditava os rumos notáveis de uma nação, desde as suas origens arquetípicas.

O texto matriz das especulações proféticas de ambos é o de Bandarra, ou o que com o teor de suas Trovas possa identificar-se. Para Vieira, o "Bandarra é verdadeiro profeta": o homem simples e de ofício humilde, praticamente analfabeto, não-religioso e descendente de judeus, mas que trazia o "lume da profecia", tal como seus pares do Antigo Testamento. Pessoa já o vê como "symbolo", o "nome colectivo", a "forma litteraria" de que se serviriam outros anônimos, com o propósito de renovar seus vaticínios. Assim, o estatuto do texto bandárrico original cede lugar às elucubrações que o "espírito da letra" permite, abstrações estas tão caras ao poeta de Mensagem. Embora tenha examinado versões diferentes das Trovas, é certo que se dedicou a comentar apenas a Explicação do terceiro corpo das prophecias de Gonçalo Yannes Bandarra, muito distante das versões próximas do que teria sido o texto original.

$\mathrm{O}$ primeiro documento público e talvez o único completo, escrito por Vieira, sobre os possíveis significados das trovas do Bandarra, é a carta dirigida

1 Cf. CANTEL, R. Prophétisme et messianisme dans l'oeuvre d'Antonio Vieira. Paris: Édiciones Hispano-Americanas, 1960. p. 175. 
ao Bispo do Japão, D. André Fernandes, origem do processo movido contra o jesuíta, pela Mesa Censória.

No caos do espólio pessoano, é quase impossível fixar o fragmento que originaria as incursões do poeta nesse campo, pois, como tivemos oportunidade de averiguar, desde muito cedo mostrou grande inclinação para buscar compreender os destinos de Portugal. Se quisermos datar o primeiro texto público, teríamos que nos remeter ao livro Quinto Império, de Augusto Ferreira Gomes, que prefaciou, onde propõe uma concepção sui generis sobre os cinco impérios do mundo, ao privilegiar a evolução espiritual dos impérios. Sob esta perspectiva, prevê o Quinto Império para Portugal, depois da Grécia, de Roma, da Cristandade e da Europa, um império do espírito e da cultura, que se contrapõe à concepção tradicional dos impérios materiais - Babilônia, Medo-Persa, Grécia e Roma -, corroborada por Vieira. Portanto, enquanto este último vislumbra um Portugal encabeçando o reino divino na Terra, o que resulta num império ao mesmo tempo espiritual e temporal, aquele insiste na idéia de um imperialismo de cultura e não de domínio e expansão.

Para reger estes destinos futuros da nação portuguesa, a partir de Lisboa, o Padre Vieira elege D. João IV ressurreto, ou quem mais possa incorporar o seu espírito, dividindo o poder com um Papa - o Papa Angélico das teorias milenaristas -, embora chefe de uma Igreja evoluída, que incorporaria posições judaicas, portanto, uma igreja ecumênica e universal. Este império teocrático contaria com a colaboração da única instituição política, segundo Vieira, capaz de reger os destinos do mundo: a monarquia.

Por sua vez, Pessoa mantém, ferrenhamente, uma postura anticatólica, sem paixão religiosa alguma, às vezes se autodenominando um "christão gnóstico" que cultiva a tendência para o ocultismo, para as formas esotéricas de conhecer o transcendente, compreendendo, também por essa via, os mais altos objetivos do seu Quinto Império. Definindo-se como um "nacionalista místico, um sebastianista racional", vê no regresso simbólico de D. Sebastião - através de uma peculiar visão das concepções de metempsicose e da reencarnação -, a potencialidade espiritual de Portugal. Assim, D. Sebastião ou o Encoberto que anuncia o Quinto Império pode ser tanto o "Presidente-Rei" Sidônio Pais quanto ele-mesmo, imbuído dos expressivos propósitos de "criador de civilização" de que se via investido.

Diferenças à parte quanto à maneira de conceber o Quinto Império, outros pontos significativos aproximam os dois comentadores de Bandarra: as respectivas obras de caráter profético são voltadas para o ideal da realização de um império futuro, calcadas em projetos incompletos, esboçados ao sabor de impulsos vertiginosos que se extravasam em discursos mais arrebatados, mal 
BOBERG, H. T. R. Padre Vieira e Pessoa: a língua portuguesa como...

conseguindo conter o entusiasmo das expressões. Obras inacabadas e fragmentárias, tecidas com idéias recorrentes, diríamos que obsessivamente recorrentes. Para compô-las, buscam fundamentações e argumentos em textos proféticos canônicos e não-canônicos, nas reflexões escatológicas, na numerologia, no esoterismo.

Isolados, cada qual, por contingências de natureza vária, no contexto social em que se albergavam, não temeram nem recuaram da postura assumida em público, a respeito dos conceitos messiânicos e proféticos.

São autores de obras que consideravam a realização máxima de suas vidas - Clavis Prophetarum, para Vieira e Mensagem, para Pessoa - produções, diríamos, emblemáticas, porque comportam a essência vital das suas ações intelectuais, a projeção mais bem acabada dos seus espíritos, justamente nos sentidos nacionalista e patriótico. Para ambos, a produção intelectual confundiase com a própria existência, uma significativa simbiose de vida-obra.

Poliglotas, propõem uma história futura para Portugal em língua portuguesa, não só por ser o idioma pátrio, mas para consagrá-la, porque sabiam, intuitivamente, que a estavam divulgando para toda a gente falante, em seus domínios ou na diáspora. Um a exaltava em prosa, o outro em verso, emprestando ao idioma o lustre impecável tanto da oratória quanto da poética. Não sem lógica Pessoa chama Vieira de "o imperador da língua portuguesa", o "maior dos prosadores portugueses, e um dos mestres da prosa em todo o mundo", 2 a ponto de assumir, na prática, e por conta e risco, toda a dimensão históricocultural da frase dita sentidamente, pelo semi-heterônimo Bernardo Soares, diante de um texto vieiriano: Minha pátria é a língua portuguesa.

Ambos propõem um império espiritual no horizonte do tempo, um império por construir com o mesmo empenho, o mesmo desejo de realização para a humanidade, a partir da vontade portuguesa de ser e de estar no mundo, conforme atesta Agostinho da Silva:

Portugal ideal em que o primeiro momento é marcado pela actuação de Vieira, cuja grandeza só pode ser plenamente aferida quando se lhe liga a figura à construção desse Brasil que afinal sonhava como base ou centro de um Quinto Império, para que Portugal

2 A primeira expressão foi utilizada no segundo poema dos "Avisos", de Mensagem, sob o título "Antonio Vieira", enquanto a segunda ilustra um parágrafo que Pessoa reservou a Vieira, num texto originariamente escrito em inglês, e ainda inédito, intitulado "All about Portugal” (Espólio, 136-58). 
provavelmente, para quem tinha olho de águia, se revelava já impotente. (...) E então, para Vieira, Portugal passa a ser não propriamente um determinado país - no qual, no entanto, ainda tenta intervir, supondo que a força acumulada no Brasil por jamais se ter aceitado no período de 1580 a 1640 qualquer interferência espanhola poderia ser transferida para Portugal -, mas sim uma ideia a difundir pelo mundo. Dizer-se Portugal é para Vieira dizerse não os graus de longitude, a latitude que ficam entre tal ou tal ponto da carta, mas o Reino de irmandade, de compreensão, de cooperação que se devia estender pelo universo como preparação necessária para um futuro Reino de Deus. Portugal estaria e seria em qualquer parte do mundo em que estivesse um português pensando à maneira portuguesa; e o centro desse Portugal era naturalmente, e porque ele aí estava, uma baía ou uma praia do Maranhão ou um pouso no Tocantins, muito mais do que os paços de Lisboa; onde, no entanto, ainda um Rei continuava, no que merecia ser apoiado, a defender um Portugal que algum dia poderia ajudar a resolver o problema de Castela; e da Europa. ${ }^{3}$

Tal pensamento não é diferente das concepções de Fernando Pessoa, como se percebe no texto que ora relembramos:

$125 \mathrm{~A}-43$

Em primeiro logar, e como já o notou João de Castro Osorio, Portugal não é propriamente um paiz europeu: mais rigorosamentese lhe poderá chamar um paiz atlantico - o paiz atlantico por excellencia. (...) Além d'isso, Portugal, neste caso, querer dizer o Brasil também. Como o impherio, neste schema, é espiritual, não há mister que seja imposto ou construido por uma só nação: pode sel-o por mais de uma, desde que espiritualmente sejam a mesma, que o são se fallarem a mesma língua. ${ }^{4}$

3 Cf. SILVA, A. da. Reflexão. 3. ed. Lisboa: Guimarães, 1996. p. 99-100.

4 LOPES, T. R. (Coord.). Pessoa inédito. Lisboa: Horizonte, 1993. p. 233. 
BOBERG, H. T. R. Padre Vieira e Pessoa: a língua portuguesa como...

Portanto, o destino que prevêem para Portugal - o de uma ação imperial no mundo, quer católica em Vieira quer espiritual e cultural em Pessoa subentende a organização de uma cooperação entre os povos, através de uma comunidade. Feitas as observações pertinentes nos textos vieirianos, por exemplo, é possível ter uma idéia da arquitetura desse império futuro. Já o percebera Raymond Cantel nas suas análises:

\begin{abstract}
A instauração do Quinto Império não implicaria, de forma nenhuma, o desaparecimento dos reinos ou dos impérios já existentes sobre a Terra. A ordem monárquica seria com efeito mantida porque isso é desejado pela Providência divina; cada nação conservaria a sua originalidade. Parece mesmo que, no pensamento de Vieira, as oposições, as controvérsias e as diferenças de interesses entre os Estados também não desapareceriam. O que era novo - e tão novo! - era que todos estes litígios seriam resolvidos pacificamente. Cada soberano delegaria, com efeito, uma parte da sua autoridade no [sic] Imperador de Lisboa e era este quem dirimiria, com o consenso geral, todos os diferendos entre as nações, causas, as mais das vezes, dos conflitos armados que despedaçavam o mundo. ${ }^{5}$
\end{abstract}

Não bastassem as convergências aqui apontadas, causa-nos especial surpresa o confronto entre as propostas de Fernando Pessoa para uma “fraternidade patriótica", a reinar no Quinto Império, e aquelas que propuseram os presidentes dos sete países falantes da língua portuguesa, nos Estatutos e na Declaração Constitutiva da Comunidade dos Países de Língua Portuguesa, por ocasião da instauração da CPLP, na cimeira realizada em Lisboa, em 17 de julho de 1996.

Reunidas as nossas observações, verificamos que Pessoa antecipa, em seus projetos, alguns tópicos, como os enumerados abaixo, essenciais para que se dê a concretização do "império da cultura", sugerindo, inclusive, providências de ordem prática:

5 Cf. CANTEL, R. Vieira e a filosofia política do Quinto Império. Tempo presente. Revista portuguesa de cultura, Lisboa, ano 2, n. 17-18, p. 24, set./out. 1960. 
1) defende a idéia de uma "fraternidade universal", que certamente dependerá de "um meio de comunicação igual", e por isso reivindica que a base da pátria e das relações sociais é o idioma:

...não somos irmãos, socialmente fallando, senão daquelles que fallam a nossa língua - e tanto mais quanto mais fallem a nossa lingua, isto é, quanto mais nella ponham, como nós, por ella ser a lingua-mãe delles, como nossa, toda a sentimentalidade instinctiva, toda a tradição accumulada, que a estructura, o som, o jogo sintactico e idiomatico trazem em si. ${ }^{6}$

2) exalta a potencialidade da língua portuguesa, quer por sua riqueza gramatical quer pelo conjunto de escritores que a ilustra;

3) preocupa-se com o patrimônio lingüístico e cultural que o PortugalAtlântico foi capaz de reunir, na sua extensão geográfica;

4) ressalta o número significativo de falantes;

5) investe na capacidade que a língua teria de se impor, espiritual e culturalmente, atendendo a uma natural tendência para o universalismo, da mesma maneira que uma vez já se impôs, materialmente, pelas descobertas, que eram, segundo o poeta, "um acto cultural";

6) observa a necessidade de estreitar os "naturaes vinculos espirituais" com o Brasil, para efetuar a propaganda que seus projetos culturais solicitavam;

7) não destina para Portugal, como Vieira o fizera, as rédeas do império futuro: "Como o impherio, neste schema, é espiritual, não há mister que seja imposto ou construido por uma só nação: pode sel-o por mais que uma, desde que espiritualmente sejam a mesma, que o são se fallarem a mesma lingua";7

8) compreende um espaço transoceânico para o Quinto Império e não apenas geográfico: "Portugal não é propriamente um paiz europeu: mais rigorosamente se lhe poderá chamar um paiz atlantico - o paiz atlantico por excellencia"; 8

9) ao contrário do que Vieira concebia, não subordina a construção do império ao jugo dos poderes temporais: "Acima da idéa do Imperio portuguez,

6 Apud SERRÃO, J. (Org.). Sobre Portugal. Lisboa: Ática, 1978. p. 122.

7 Cf. LOPES, op. cit., p. 233.

8 Id. 
BOBERG, H. T. R. Padre Vieira e Pessoa: a língua portuguesa como...

subordinado ao espirito definido pela lingua portugueza, não há formula politica nem idéa religiosa"; 9

10) preocupa-se com a preservação do idioma, a ponto de sugerir a fixação do "etymologismo orthographico": "É bem o systema que, como por milagre, representa e se ajusta á missão historica de Portugal..."

Todas essas ponderações revelam a idéia de um império voltado para a necessidade de se cultivar o espírito civilizacional, de projetar-se no mundo, não como pátria-povo, mas como língua-pátria, e de buscar a sonhada "fraternidade patriótica" ou a conquista da identidade pela língua. Sobre essa concepção de Quinto Império, perfeitamente coesa à idéia da simbiose obra-vida de que já falamos, Agostinho da Silva já antevia, em 1959, a necessidade de um destino comum para os povos de língua portuguesa:

É por esse Império, que nem ele nem os seus companheiros têm a coragem ou a força ou a hora de construir, porque numa história movida por Deus tudo vem a ser o mesmo; é por esse Império, que não tem lugar marcado nos mapas porque vive no sorriso, no olhar, nos sonhos dos meninos; é por esse Império, que se tornará consciente ou inconsciente a nós, como se torna consciente ou inconsciente a uma criança o que, dormindo, a faz sorrir; é por esse Império, que só poderá surgir quando Portugal, sacrificandose como Nação, apenas for um dos elementos de uma comunidade de língua portuguesa; é por esse Império, que já foi aurora de realidade e que hoje é apenas o cavo passo que se escuta em palácios desertos, que Fernando Pessoa pensa, escreve, concebe génios, sofre recolhido e ignorado morre. ${ }^{11}$

Ora, são aquelas também as propostas e as metas que pudemos captar nos vários documentos que anteciparam a criação da Comunidade dos Países de Língua Portuguesa, bem como nos próprios documentos institucionais, além das vozes dos próprios Chefes de Estado, enquanto portadores do pensamento de seus povos, diante da instituição recém-criada. Como que inspiradas pelas

9 LOPES, op. cit., p. 240.

10 Trecho do ensaio inédito que se encontra no espólio, sob a denominação 123B96/100.

11 Cf. SILVA, A. da. Um Fernando Pessoa. 2. ed. Lisboa: Guimarães, 1988. p. 90-91. 
diretrizes pessoanas, as orientações discriminadas no primeiro encontro da CPLP têm, por escopo, a preservação do espírito fraterno entre as nações, a potencialidade cultural expressa na língua, a defesa do patrimônio comum, histórico e cultural, a crença no princípio da comunidade enquanto forum de concertação e cooperação, nos campos social, econômico, político e cultural, e a preocupação com a preservação do idioma, mormente nos países africanos de língua oficial portuguesa. Não falta nem mesmo a idéia da "imposição" da língua no contexto cultural mundial.

A par dos anseios políticos expressos naquela ocasião, percebemos a permanência e a multiplicação de um ideário desde sempre conclamado pela plasticidade da língua, qualquer que seja o recanto em que é utilizada. Daí a recorrência dos conceitos de fraternidade, da língua como fator de união, da busca pelo universalismo, e do consenso de que, pela língua, se há de conseguir impor uma visão de mundo mais espiritualizada, de acordo, portanto, com a atual tendência da humanidade para os valores da afinidade e do bem-estar dos povos.

Talvez essas circunstâncias expliquem a sobrevivência de uma conjuntura de idéias semeadas, quem sabe, nos textos proféticos do Antigo Testamento, cultivadas pelo imaginário de uma certa nação e alimentadas por alguns homens que tinham uma determinada visão da história pátria e que, com suas vozes proféticas inspiradas, convidam as gerações futuras a repensar o futuro dessa nação, não mais como nação-povo, porque geograficamente se expandiu, mas como pátria de uma língua que só tem a pretensão de ser mais humana. Quem sabe possam justificar, inclusive, a nossa própria pesquisa, ou, como diríamos junto com Agostinho da Silva, a nossa missão:

Do rectángulo da Europa passámos para algo totalmente diferente. Agora, Portugal é todo o território de língua portuguesa. Os brasileiros poderão chamar-lhe Brasil e os moçambicanos poderão chamar-lhe Moçambique. É uma pátria estendida a todos os homens, aquilo que Fernando Pessoa julgou ser a sua Pátria: a língua portuguesa. Agora, é essa a Pátria de todos nós.

Quando se diz ter Portugal de fazer alguma coisa, o que tem de ser feito sê-lo-á por todos os homens de língua portuguesa. A missão de Portugal, agora, se de missão poderemos falar, não é a mesma do pequeno Portugal, quando tinha apenas um milhão de habitantes, que se lançou ao Mundo e o descobriu todo, mas a missão de todos quantos falam a língua portuguesa. Todos esses povos têm de cumprir uma missão extremamente importante no Mundo. ${ }^{12}$ 
BOBERG, H. T. R. Padre Vieira e Pessoa: a língua portuguesa como...

\title{
RESUMO
}

O Padre Antônio Vieira e o poeta Fernando Pessoa abraçaram a causa do Quinto Império sob pontos de vista que se aproximam: o primeiro vislunbrava-o como um império português, terreno, dominado por uma Igreja ecumênica, enquanto o outro propunha o império da língua portuguesa, enquanto língua de cultura, uma pátria espiritual, simultaneamente portuguesa e universal. Seus pontos de vista refletem um contexto cultural, que foi também assimilado pelos demais povos que têm a língua portuguesa como oficial, conforme atestam os discursos dos Chefes de Estado dos sete países falantes, ao criarem a Comunidade dos Países de Língua Portuguesa - CPLP.

Palavras-chave: Profecia, Quinto Império, língua portuguesa.

\begin{abstract}
The priest Antonio Vieira and the poet Fernando Pessoa embraced the Fifth Empire cause under points of view that approach each other: the first envisioned it as an earthen Portuguese empire, dominated by a ecumenical church, while the other proposed a Portuguese language empire, as a language of the culture, a spiritual nation, simultaneously Portuguese and universal. Their points of view reflect a cultural context, that was also assimilated by the other countries who have Portuguese as the official language, as attested by the pronouncements of the Chiefs of State of the seven speaking countries, at the creation of the Comunidade dos Países de Língua Portuguesa-CPLP (Portuguese Language Countries Community).

Key-words: Prophecy, Fifth Empire, portuguese language.
\end{abstract}

\section{REFERÊNCIAS}

CANTEL, R. Prophétisme et messianisme dans l'oeuvre d'Antonio Vieira. Paris: Édiciones Hispano-Americanas, 1960.

. Vieira e a filosofia política do Quinto Império. Tempo presente. Revista portuguesa de cultura, Lisboa, ano 2, n. 17-18, set./out. 1960.

12 Cf. MEndanha, V. Conversas com Agostinho da Silva. 2. ed. Lisboa: Pergaminho. p. 30-31. 
BOBERG, H. T. R. Padre Vieira e Pessoa: a língua portuguesa como...

LOPES, T. R. (Coord.). Pessoa inédito. Lisboa: Horizonte, 1993.

MENDANHA, V. Conversas com Agostinho da Silva. 2. ed. Lisboa: Pergaminho, 1995.

SERRÃO, J. (Org.). Sobre Portugal: introdução ao problema nacional. Lisboa: Ática, 1978. p. 122.

SILVA, A. da. Reflexão. 3. ed. Lisboa: Guimarães, 1996.

Um Fernando Pessoa. 2. ed. Lisboa: Guimarães, 1988. 